\title{
The balance paradox of management
}

\author{
Tadeusz GOSPODAREK \\ WSB University in Wroclaw, Poland
}

\begin{abstract}
:
Aim: There exists an inequilibrium between the available quantity of goods and the level of consumption resulting in local economic polarisations and asymmetric capital concentrations. Replacements of real money with derivative instruments cause strong perturbations on capital markets. Consumer preferences change towards the maximization of the utility of the used capital. The above observations are a basis for the hypothesis that managers, in general, prefer to maximize the momentum profit regardless of the risk of losing the stability of macroeconomic systems.
\end{abstract}

Design/Research method: It is heuristic about the objective function of an organization based on observations, that there are two excluding tendencies in formulating goals: to maximize the profit (using all possible opportunities) and simultaneously to achieve stability in the long run (keeping the micromacro balance).

Conclusions/findings: Managements cause deviations from the micro-macro balance, and at the same time trying to keep this balance. This leads to the following paradox of management (the balance dilemma of management): Managers always try to maximize opportune profits, regardless of future benefits that may be derived from keeping the equilibrium. And conversely, rational long-term stability suggests postponing most opportunities and keeping external boundaries (e.g. realizing sustainable development). However, managers' temporary preferences lead to an increasing number of unbalanced interactions between organizations and their surroundings, up to the critical point when some catastrophic economic processes may take place.

Originality/value of the article: Original heuristics based on the observations of some micro-macro economic balance relations in business practice.

Implications of the research: One more paradox in the theory of management have been presented. It is important for base statements of the theory of organizational bahaviors consistency and inferring would be more accurate.

Key words: General economic equilibrium, rationally bounded decisions, paradox of management, micro/macro balance, management theory.

JEL: L2, M21, D5, F41

Correspondence address: Tadeusz Gospodarek, WSB University in Wrocław, ul. Fabryczna 29-31, 53609 Wrocław, Poland. E-mail: tadeusz.gospodarek@wsb.wroclaw.pl.

Received: 08-08-2017, Revised: Revised: 22-02-2018, Accepted: 22-02-2018

doi: http://dx.doi.org/10.29015/cerem.526 


\section{Introduction}

"Greed is good" was Gordon Gekko's favorite saying in Oliver Stone's movie "Wall Street". Today, even Pope Benedict XVI in his encyclical "Caritas in veritate" accepts the situation in which "man is organically aimed at achieving more". How does the manager make his decision against these assumptions? It is a purely behavioral action - catch as catch can.

This paper is addressed to researchers who try to formalize the theories included in management knowledge. It primarily focuses on the problem of inconsistency of the base statements of economic balance theories explaining the goals of management. It means that using the same base statements of the theory, one can conclude the sentence where either true or false logical value assignment is possible. It is a paradox, and the balance paradox of management (Quinn (1988) is one more discovered and explained here.

Economic theories should be judged by three criteria: congruence with reality, generality, and tractability (Stigler 1965). But what if the theory offers paradoxical conclusions? In formal sciences, it is forbidden because of scientific restrictions in methodology. But it works in social sciences, mainly due to complexity of theoretically the issues described, and it sometimes leads to serious problems in the real world. For example, managers would maximize an objective function if they knew it was wrong, but despite this knowledge, their decisions are taken against rational aspects (Simon 1957). The existing ceteris paribus in social science makes all the generalized approaches far from certain, and nobody claims that this uncertainty is easy to estimate. All managerial decisions are related to the future and taken on the basis of some present and past data under the conditions of uncertainty, which is the only possible method of predicting, but due to weakness of the economic theory and the mentioned complexity, the resulting conclusions may be far from the assumed data. The subjective aspects of decision-making generally lead to future consequences, not always achievable or predictable.theoretically. It is also the main problem of general economic forecasting which was a faux pas in relation to the present crisis. The quantitative methods regarding those elaborated by operational research are not sufficient for exact crisis forecasting and it is probable 
that nothing will change in this matter soon.

One of the most important attempts to analyze the economic equilibrium is the Arrow-Debreu-McKenzie (ADM) model (Debreu 1959; Arrow \& Hahn 1971). The outcome of competitive markets in an open economy is modeled as a Walrasian equilibrium, which is an allocation together with a price system that is characterized as follows:

- Each organization maximizes profits, taking prices as given.

- Each consumer maximizes preferences as subject to their budget constraint.

- All markets are clear (both parts of the game have full information, and the entrance to the market is free from barriers).

This is the basis of rational management. But it is easy to see that the objective function derived from the above may not be the most desirable because managerial decisions may be inadequate (Steinar E. and Wilson R. 1974). Then the requirements of the ADM model are not met and, as a consequence, the general economic balance is distorted. The ADM model applies to economies with maximally complete markets, in which there exists a market for every time period and forward prices for every commodity at all the time periods and in all places. Therefore, an analysis of all deviations from the above assumptions would be a basis for determining possible economic problems. Also, it may be a basis for evaluations of management decisions. Moreover, if this is so, then a reverse statement about the existence of a micro-macro balance as an indicator of the fulfillment of the ADM requirements is a correct analytical method (at a minimum qualitative level). Analyzing local deviations from the micro-macro balance for the purposes of reasoning about the clarity of the market seems to be correct then.

Management science is continuously looking for good methods of forecasting and good models of economic behaviors, because it seems probable that each new crisis may be stronger and goes faster than the previous one. The success of behavioral economics (Camerer \& Loewenstein 2003) and its methods needs to take into account some irrational mechanisms of management decisions prior to the quantification approach and precise operational research methods. For that reason, the most important approach to crisis forecasting seems to be the analysis of deviation from a stable micro-macro balance and estimations of its possible 
quantified results and non-measurable consequences.

Because most business activity may be treated as a set of games against the surroundings, it is possible to define the payoff function as a micro-macro state of balance, and understood as an equation of some macroeconomic parameters. Until this moment, the ADM model in its pure form may be accepted. In general, the macro balance is stabilized by the authorities at the regional or governmental level, manifested by introducing to the game some boundaries, law regulations, tax policy, governmental support, etc., thus reducing the open form of economy to the restricted type. The micro balance depends on entrepreneurial activities and local business interactions, and most of the strategies chosen are directed towards a maximization of temporary profit. Sometimes these games are of the open type but in most cases they are closed ones, in which the payoff function describes the micro-macro balance. All possible deviations from the micro balance are related to a competitive act (eliminating competitors from the market, expansion beyond the local surroundings, catastrophic behaviors of the bankruptcy type). But due to behavioral and opportunity-related actions, some cheating strategies in the game are possible (creative bookkeeping, hidden profit, payment cheatings, etc.). This often causes unbalanced perturbations from the micro-macro balance (e.g. the classic Enron case), which may induce large-scale crisis situations. Therefore, the ADM model may not be entirely acceptable and the calculated deviations may be treated as signals of possible economic inequilibrium.

Figure 1 presents the model of micro and macro balance existing in an economical system based on the game model of interactions between an organization and its surroundings. The Nash equilibrium represents a saddle point of the game. It always exists if the game may be represented in a matrix form (matrix games). All the erroneously chosen strategies and rationally bounded decisions induce the most vicious response from the surroundings, and result in a loss of payoff (deviations from the micro balance state). The Debreu equilibrium is derived from the theory of value and may be understood as a macro state of the average micro-macro interactions. But if all deviations from the micro-macro balance observed in a given time and generated by managerial decisions do not compensate each other, then the superposed deviation signal will cancel the macro balance. And it may be one of the 
theoretical explanations of a crisis arising. After some time, when precise financial data were available, it would be possible to apply the ADM model and try to find some interesting quantitative estimations of the observed deviations. But now it is only possible to present some qualitative and heuristic information.

According to Simon's theory (Simon 1957), most management decisions are rationally bounded. It is therefore obvious that most of them will be oriented towards taking advantage of any local and temporary opportunities. It is almost a paradigm of the new management theory. For that reason, it is probable that after some time a strong deviation from the micro-macro economic balance will take place. This period of time will be proportionally shorter the more opportunities in the surroundings occur and are taken advantage of. The place of the strongest deviations from the micro-macro balance will be restricted to the most active entrepreneurship business centers and places related to big capital concentrations. This process is unstoppable, it is therefore obvious that sustainable development is only a nice theoretical model, adequate for an equilibrium economy in a finished time. The following questions may also be posed: Is the ADM model a sufficient tool for explaining the economic crisis? Can the global economy be still seen as an open economy type? May the global economic balance in Debreu's sense be assumed when replacements of money and derivative instruments are in common use? These questions are very difficult to answer, taking into account the existing crisis situation. For further discussion, it is necessary to introduce some case studies which would clarify the presented analysis. 
Figure 1: Micro-macro balance in relation to Debreu and Nash equilibrium

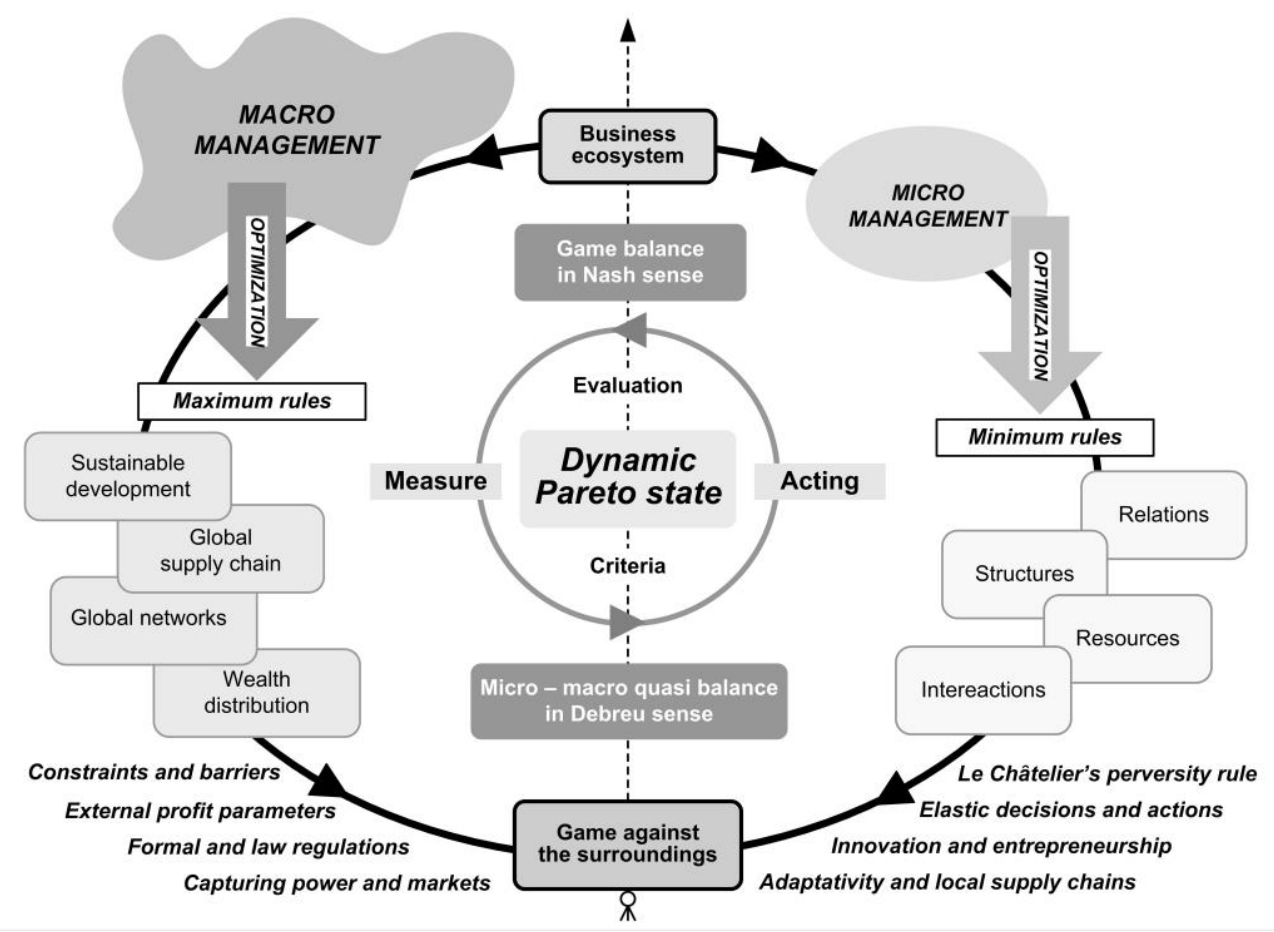

Source: author's own elaboration.

\section{Sustainable development in the $\mathbf{E U}$ as an example of macro balance}

In human nature, risk aversion is one of the most important aspects of decision making. It is probably one of the bases for seeking economic systems and behaviors where stabilization at the micro level is fixed and easy to forecast. The sustainable development concept is an example of such thinking on the macro scale (UCN 2006). It is an ontological model of economic behaviors in which the micro-macro balance of the system is stable in a long time period and where such phenomena as speculation bubble are not available (or strongly reduced), and the investment risk is reduced to a minimum. In practice, sustainable development is realized by macro planning and project managing in the EU. This planning is carried out at all levels of regional governance, where the smallest unit is the municipal unit. All units prepare 
strategies of development where a 6-year period of investment is composed of a set of possible projects. It is the basis for the European Commission to plan the central budget and introduce global programs of development. One of the most important among them is the European Regional Development Fund (ERDF) ${ }^{1}$. All ERDF cofinanced projects are subjected to a formal logical frame approach, the procedure of evaluation and analyzed in detail before any funds are granted. Therefore, long-term effects of such planned investments improve the economic situation of the less developed regions and, thanks to activating their potential of value added creation, it results in powerful feedback for the global impact of EU economy. The existence of a micro-macro economic balance may be observed here, and there are different mechanisms regulating the volume of the offered aid regarding the average economic situation of EU regions, as presented by Eurostat ${ }^{2}$. In this way, some regions do not participate in the EFRR program (e.g. London City), whereas e.g. the Polish eastern borderland regions are beneficiaries of the EU aid to a maximally acceptable level. But after some time, this economic activation will also bring positive macroscopic effects, reducing the EU economic-aid involvement. In the economic growth of the EU countries, the maximum impact of investment is focused on infrastructure projects such as: highways, waste-water utilization, waste deactivation, pure water and air. The quantities invested are huge. In case of Poland, it is over 60 billion euro for 6 years financial perspective. If we add the self-partnership capital, then the amount of around 20 billion euro indeed accounts for considerable investment power. And it is for this reason that the internal consumption is strong, resulting in the fact that during the present economic crisis, the economic situation in Poland remains among the best in the whole EU.

This macroeconomic mechanism is one of the important factors in the reduction of adverse effects of the crisis. It is also important that Poland is not too engaged in the international financial circuit. Polish banks and big financial organizations are not involved in subprime mechanisms or other money replacement products as differential instruments. It may be assumed that due to the weak engagement in global supply chains and the global financial exchange, Poland is more resistant to

\footnotetext{
${ }^{1} \mathrm{http} / / /$ ec.europa.eu/regional_policy/funds/feder/index_en.htm

${ }^{2}$ http://epp.eurostat.ec.europa.eu/portal/page/portal/eurostat/home/
} 
the crisis. All EU statistical data received from Eurostat show that sustainable development of EU regions is the right direction of economic growth.

The conclusion is that the EU model of sustainable development, represented by the ERDF program, is an example of the support of macro balance, which allows a stable economic growth of a region. It makes regions more immune to local crisis situations. Highly formalized procedures of investment protect against subjective and rationally bounded management decisions. However, in the planning practice, it may be observed that the national development strategy was not exactly derived from district and branch strategies.

Can we observe any paradoxical management behaviors in the presented case? The answer is "yes". All managerial decisions related to the ERDF fund distribution are related to political aspects and particular benefits, often regardless of any economic sense. One of the best examples is the Polish set of macro management decisions about the ERDF capital distribution and procedures of its use and handling, which were purely nonsensical, and in the nearest future the absorption of all the available funds will become a real problem. Managing authorities are strongly influenced by politics and therefore most decisions are rationally bounded. As a result, one can observe an additional economic polarization instead of sustainable development of all Polish regions. Also, an important part of the funds will be lost due to a lack of regional, mainly municipal, capital.

\section{How to disturb the micro-macro balance from a macro point of view?}

The conclusion may be supported by experiments with options in currency rates in relation to the international speculation against the Polish zloty (PLZ). Within the period of half a year (from August 2008 to March 2009), the exchange rate of PLZ/\$ changed by $75 \%$. The same situation was observed for the rates of PLZ/euro and PLZ/yen. Now we have a reverse situation. The exchange ratio is rising by up to $50 \%$ in relation to March 2009 minimum. Why? There is no economic explanation to this kind of behavior. But Poland is not an island on the ocean of economics. The surroundings found the opportunity for an easy way to earn quick money, disturbing 
the existing macro balance in the process, of course. A lot of false information was coming from the surroundings, including signals which were important in taking business decisions. This information was cleverly prepared by banks, some influential people, opinion-making centers, etc. They created an impression that the zloty was getting stronger and stronger despite the rationally justified signals stemming from the real economic data. At that moment, clever bankers started selling options on the currency ratio, having the knowledge that the offered products are pure cheat. Simultaneously, some external corporations started speculating against the zloty, setting the depreciation of its rate at above $75 \%$ in a short period of time. As it was easy to predict, a lot of buyers of toxic options ended up falling into a critical economic situation. But for the surroundings, nice profits were reaped.

The conclusion is that any disturbance of the micro-macro balance due to managerial decisions induces some catastrophic reactions, which may result in a crisis situation. The enterprises which are more involved in toxic transactions may go bankrupt.

Where does the paradox of management lie? The answer is simple. Regardless of the existing risk and the necessary knowledge of derivative instruments, some managers decided to buy toxic financial instruments anyway. They broke the micromacro balance for some dubious short-time profits. The punishment proved severe. Some enterprises went down, becoming sad evidence of catastrophic behaviors on a local scale. What is more - this situation is easily expandable into the entire surroundings.

\section{Entrepreneurial decisions (micro balance perturbations)}

Let us have a look at the structure of decision making presented in Figure 2. The main stream of decisions are behavioral actions of the entrepreneur. In general, they are induced by temporary opportunities. Entrepreneurial decisions are therefore affected by the surroundings in a positive and/or negative way as information feedback. The positive interactions include stimulations (e.g. governmental support, external funds, etc.) and free information exchange (e.g. knowledge diffusion from 
the surroundings, support based on the web 2.0 concept, etc.). The negative aspects include all the regulations (legal restrictions, taxes, free law interpretations, etc.), boundaries (different protection rules, social demands, etc.) and pathological interactions (e.g. corruption, paid concessions, hidden taxes, etc.). The above interactions are related to the micro-macro balance and may be analyzed by the SWOT and PEST methods. But it is possible to distinguish an internal core of entrepreneurial decisions, representing the operational aspects of the micro-macro interaction. The subjective aspects are rationally bounded decisions of the entrepreneur toward any changes of the objective function. A visionary entrepreneur can take the risk of changes without precise, quantitative data, but he can take into account some rational aspects derived from the surroundings. But all entrepreneurial decisions are related to taking advantage of opportunities, thus introducing some kind of micro-macro balance perturbation. What if this perturbation is important and difficult to compensate by the surroundings? Some enterprises may go bankrupt in a catastrophic form and are not replaced with new ones. A good example may be the decline of the local linen and cotton industry, replaced by imported fabrics, which began a 20-year long crisis situation in the region of Lower Silesia in Poland.

The conclusion is that entrepreneurial decisions may change the micro-macro balance regardless of the rational aspects of stabilization in the long run. Decisions tend to be behavioral and redirected onto changes of the entrepreneur objective function toward a temporary maximization of profit.

The paradox of management is clear. Entrepreneurial decisions are related to the easiest changes of production results, eliminating the local suppliers of fabrics and replacing them with cheaper imports or any other form of outsourcing service using Global Supply Chain possibilities (Neace \& all. 2013). It destabilizes the temporary local macro-economic balance and in the long run leads to some negative consequences. 


\section{The objective function}

Let us now have a look at the descriptions of strategic schools. The fundamental assumption of all strategies is how to defeat the competitors. In other words, how to achieve a competitive advantage and how to take advantage of the chances in the surroundings. Such a determination of strategic aspects suggests the objective function, where the optimum is related to temporary success. Even the real option school of management (Dixit \& Pindick 1994) shows a way to fulfill such assumptions in the shortest and the most effective way. But what if the optimized function is wrong? An improper optimization may lead to catastrophic behaviors and clearly interrupts the existing micro- or micro-macro balance. But managerial decisions are subjective and therefore rationally bounded, strongly influenced by the policy and probable incentives resulting from a fast success. Therefore, the objective function realized by a typical manager is not directed toward a long-term sustainable development, but toward immediate, quick success.

The conclusion is that strategic management introduces the objective functions which may affect the existing micro-macro balance. The behavioral aspects of strategic decisions define short time functions redirected onto quick profit. As a result, even some cheating mechanisms in management decisions are also observed (like e.g. selling toxic financial instruments fully aware of this fact).

The paradox of management is clear here. When better incentives are offered to a manager, then quicker objective functions redirected onto medial success and appropriation of payoff are preferred, regardless of all the balance aspects.

\section{Hidden knowledge utilization}

One of the most dangerous aspect of the destabilization of the micro-macro economic balance seems to be discovery and the use of tacit knowledge and tacit utility of resources. Sometimes a revolutionary concept rolled out into practice may induce unforeseen results. Some financial engineering experiments with derivative instruments are the best examples. Introducing replacements of real money with 
substitutes makes the fundamental Arrow-Debreu-McKenzie model of general economic balance insufficient. Sometimes business receives an extraordinary product from scientific laboratories. What is the main aim of the management, then? To register a patent as soon as possible and cut off the competitors, then to sell as much as possible regardless of the potential long-term consequences both for the seller and for the surroundings. This process is analogical to any self-induced reaction in nature: it is irreversible and unstoppable. Sometimes hidden knowledge is very dangerous but nobody cares about that. There are some interesting examples of replacing technologies in a catastrophic way (e.g. the replacement of CRT monitors with LCD technology) together with the positive and negative results observed.

The conclusion is that hidden knowledge and utilization of resources are a basis for potential deviations from the micro-macro balance, and sometimes for the macro balance. Because knowledge-based entrepreneurial activity is strongly supported by world capital, possible unbalanced business processes will develop. In some cases, it may induce catastrophic behaviors in the area where industrial processes will stop due to technological elimination. The paradox of short-term preferences instead of long-term balance protection is clear. All management decisions will be redirected onto quick profit.

\section{Rationality-bounded decisions and the economic balance}

As pointed out in the cases presented above, most management decisions are rationally-bounded and of the behavioral type. Majority of strategic decisions are oriented towards local opportunities. This process of quick success orientation is unstoppableand therefore micro-macro balance deviations will always be observed. The second general conclusion drawn from the micro-macro balance perturbation consequences caused by management processes may be formulated as follows: because of the bounded rationality of management decisions taken in uncertain circumstances, the category of open economy in Debreu's sense does not exist in practice and serious deviations from the model are observed. All our economic surroundings are more or less restricted by boundaries, rules and rights, and tend to 
change periodically as a result of arising hidden opportunities. The hidden opportunities may derive from the hidden utilization of the available resources and information processing (including that of tacit knowledge). Thus, all the quantitative approaches based on certain data processing and ex-post-based forecasting are useless in forecasting crisis situations.

Sustainable development is a nice idea, but its practical usage seems impossible, regarding the tendencies among strategic schools. The case of the ERDF program presented above, is a positive example of the solution of one aspect (the right use of big capital during a long period of time). But full realization of sustainable development requires a co-operation of entrepreneurial acts closely related to governmental projects. And because of management decisions focused on quick success, the long-term stabilization programs only make the surroundings less turbulent. Much has been written about possible causes of the global financial crisis, but the following factors seem to be the most responsible:

- The barrier between the capital markets and banking has been affected by faulty or dishonest financial innovations, especially derivative instruments and money replacements offered worldwide without certain information.

- All incentives for the employees of financial institutions have been geared to short-term profits instead of long-term benefits, which serves as one of the best exemplifications of the management paradox described in this paper. This mechanism seems to be impossible to eliminate in the future, which will in turn generate further deviations of the micro-macro balance.

- Risk insurance has been neglected on the macro scale, and true information about possible consequences of the use of risky instruments has been hidden. Therefore, managerial decisions to invest in toxic instruments have been of the bounded rationality type.

- Financial institutions have been excessively leveraged and their activities not transparent enough or subjected to suitable control procedures. In conjunction with the incentives system for managers, temporary benefits have been preferred to longterm sustainable development.

- Inadequate macro balance stabilization activities of politicians and governments based on pumping capital into less recognized and evaluated critical points of 
destabilization have been examples of bounded decisions related to temporary effects disregarding long-term consequences.

All the presented cases show that rational aspects of managerial decisions are affected by various factors and there is no way to eliminate subjective and behavioral acts. What is more, the interactions between financial corporations and business will always be a kind of game where the micro balance is not its fundamental payoff.

\section{Conclusions}

In conclusion, the main objective of this paper has been to propose the following statement: One of the most important factors in all economic crisis situations is the balance paradox of management. It means that, despite the rational sustainable development and socially accepted long-term strategies, managements make rationally-bounded decisions focused on temporary and quick appropriation of payoff regardless of the possible serious deviations from the micro-macro economic balance.

Globalization, present in the global supply chains, networking and over-national management, leads to capital concentration and macro-economic balance oscillations. Sometimes a deviation from the micro-macro balance is so strong that the global system is not able to compensate for it. It may then be possible to start self-inducing processes of chaotic capital flow without control, which may cause critical economic behaviors on a large scale.

Based on the deviations from the Nash equilibrium at the micro-macro level, and the deviations from the Arrow-Debreu theory of value and general economic balance, and also taking into account the use of derivative instruments and faulty financial engineering, it is possible to theoretically explain the economic mechanisms of a crisis.

Behavioral economics seems to be the most valuable tool in explaining managerial decisions with bounded rationality and deviations from the micro-macro economic balance. Because the psychological aspect of the micro-macro balance perturbation seems to be the most important, it is impossible to avoid crisis situations 
in the future. There are no suitable tools for crisis forecasting and due to the lack of reliable semi-quantitative models of the formation of speculation bubbles along time, our knowledge of future deviations from the macro-economic balance would be uncertain. Because the balance paradox of management seems to be impossible to eliminate, our tacit knowledge about crisis forecasting will remain hidden.

\section{References}

Camerer C., Loewenstein G. (2003), Behavioral economics: Past, present, future", in: Advances in behavioral economics, eds. Camerer Ce., Loewenstein G., Rabin M., Princeton University Press, Princeton, pp. 3-51.

Debreu G. (1959), The theory of value, John Wiley, New York.

Dixit A.K., Pindyck R.S., (1994), Investment under uncertainty, Princeton University Press, Princeton.

Neace M.B, Gospodarek T., Neace X.G., (2013), Global supply chains as holistic systems: an expanded perspective, "Int. J. of Economics and Business Research", vol. 5 no. 2, pp. 165-182

Quinn R. E. (1988), Jossey-Bass management series. Beyond rational management: Mastering the paradoxes and competing demands of high performance, Jossey-Bass, San Francisco, CA, US.

Simon H.A. (1957), Administrative behaviour, Free Press, New York.

Steinar E., Wilson R. (1974), On the theory of the firm in an economy with incomplete markets, "Bell Journal of Economics and Management Science", vol. 5 no. 1, pp. 171-180.

Stigler G. (1965), The development of utility theory, Chpt. 5 (in: Essays in the History of Economics) University of Chicago Press, Chicago.

UCN (2006), The future of sustainability: Re-thinking environment and development in the twenty-first Century. Report of the IUCN Renowned Thinkers, Meeting, 29-31 January. 